\title{
Do acute diseases transiently impair anterior pituitary function in patients over the age of 75 ? A longitudinal study of the TRH test and basal gonadotrophin levels
}

\author{
M. Impallomeni, B.M. Kaufman ${ }^{1}$ and A.J. Palmer ${ }^{2}$ \\ Geriatrics Services Unit, Department of Medicine, Royal Postgraduate Medical School, Hammersmith \\ Hospital, Du Cane Road, London W12 0HS; ' Care of the Elderly Unit, Central Middlesex Hospital, \\ London and ${ }^{2}$ Epidemiology Research Unit, Geriatrics Division, Department of Medicine, Royal \\ Postgraduate Medical School, London, UK
}

Summary: Several studies have shown that anterior pituitary function is affected by the ageing process. Little is known, however, about the effect acute diseases have on the anterior pituitary. Should they be associated with a disturbance of anterior pituitary hormone production, they might make anterior pituitary function tests difficult to interpret when they are most needed.

To test this hypothesis, we studied the thyrotrophin (TSH) releasing hormone (TRH) test and basal plasma gonadotrophins, taken as indicators of anterior pituitary function and reserve, in 74 consecutive patients (49 women) mean age $82 \pm 5.1$ suffering from acute diseases soon after admission to hospital. $A$ total of $\mathbf{4 4}$ (30 women) were followed up and retested after 3 disease-free months following recovery and discharge home. Seventy-one age- and sex-matched healthy controls (47 women), mean age $82 \pm 5.0$ living in the community were also studied.

The mean peak TSH increment after TRH (mean $\Delta_{\max }$ TSH) increased from 5.7 soon after admission, to $7.7 \mathrm{U} / 1$ at follow-up $(P=0.01)$. The mean plasma $\mathrm{LH}$ increased from 25 to $35 \mathrm{U} / 1$ in women $(P=0.0004)$ and from 9.7 to $14 \mathrm{U} / 1$ in men $(P=0.03)$. The mean plasma FSH increased from 21 to $25 \mathrm{U} / \mathrm{l}$ in women $(P=0.04)$ and from 7.5 to $9.4 \mathrm{U} / 1$ in men $(P=0.01)$. Controls had greater TSH responses to TRH and higher plasma gonadotrophins levels when compared with acute patients (LH women $P=0.17$, for all other tests $P<0.05$ ).

We conclude that a transient reduction of anterior pituitary function is a common occurrence in patients over the age of 75 suffering from acute diseases. This has diagnostic relevance and therapeutic implications.

\section{Introduction}

The interplay of advancing age, disease and pituitary function is still not fully documented, despite the recent development of an impressive array of dynamic tests of anterior pituitary function. ${ }^{1,2}$ These have proved invaluable in investigating younger subjects but less so in the elderly. ${ }^{3}$

In a previous study of anterior pituitary function and reserve in hospital in-patients over the age of 75 in early convalescence, we found that many gave results that in younger people would have indicated impaired anterior pituitary function ${ }^{4}$ with the exception of ACTH function which was well preserved. It was unclear whether this difference was the result of physiological ageing, and therefore irreversible, or the non-specific and possibly transient effect of disease.

Correspondence: M. Impallomeni, M.D., F.R.C.P. Accepted: 1 September 1993
The diagnostic use of measurements of plasma levels of hormones depends on the ability to relate the measured levels to physiological and pathological changes in the gland where these specific molecules originate. Should a transient impairment of anterior pituitary function occur during acute diseases in the elderly, it could not only confuse the interpretation of these tests when they are most needed, as they are generally carried out on sick subjects, but also suggest a therapeutic intervention to remedy this deficiency. The duration of this deficiency would be an invaluable aid to indicate the duration of possible therapy.

In order to test this hypothesis we carried out a longitudinal study of the TRH test, and of the baseline gonadotrophins levels, as indicators of anterior pituitary function and reserve. The gonadotrophins are normally elevated in postmenopausal women, when the absence of the negative feedback of ovarian hormones on the anterior pituitary acts 
as a natural stimulation test. ${ }^{5}$ Such elevation is less consistent in men, as the male menopause occurs later, its onset is more variable in time and is best indicated by a fall in plasma testosterone level. ${ }^{6,7}$

We performed the TRH test, and measured plasma luteinizing hormone ( $\mathrm{LH})$, follicle stimulating hormone (FSH) and, in men, testosterone, in recently admitted elderly patients suffering from a variety of acute diseases. These were repeated not less than 80 days after recovery and discharge home. We also compared the patients with healthier ambulatory controls, free from acute diseases, living in the community.

\section{Patients and methods}

A total of 78 patients admitted to the geriatric wards at the Hammersmith and Central Middlesex Hospitals suffering from acute diseases were selected. These were the first two patients over the age of 75 admitted each week, capable of giving informed consent. Patients with conditions known to interfere with anterior pituitary function, such as thyroid disease, obesity, dementia, depression, or taking drugs known to affect it such as L-dopa or corticosteroids, ${ }^{4,8}$ were excluded. Patients were considered euthyroid if their plasma total thyroxine was within our laboratory reference range, or if outside it, their plasma thyroid stimulating hormone (TSH) was within the reference range. ${ }^{9}$ Two patients were found to have biochemical evidence of previously unsuspected myxoedema; one to have previously unsuspected thyrotoxicosis, one other was found to have been on prednisolone for chronic obstructive airways disease at the time of admission. These four individuals were omitted from the analysis of results.

This left 74 patients for study: 49 women and 25 men, mean age $82 \pm 5.1$. The main presenting pathological condition for each patient on admission was: left or biventricular heart failure in 22 patients, chest infection 10 , cerebrovascular accident 8 , cellulitis of legs 7 , myocardial infarction 6 , urinary tract infection 5 , bleeding from peptic ulcer 4 , septicaemia 2 , biliary tract infection 2 , generalized epileptic fit 2 , food poisoning 1 , hyperosmolar non-ketotic diabetic coma 1 , deep vein thrombosis 1 , severe pernicious anaemia 1 , sciatica syndrome (prolapsed lumbar disc) 1 , and shingles 1 .

Subjects were not fasted; half an hour after the insertion of an intravenous cannula and with the subject resting, a blood specimen was drawn for estimation of plasma TSH, LH and FSH, total thyroxine and testosterone in men only. Soon after, a bolus of $200 \mu \mathrm{g}$ of TRH (protirelin, Roche) was injected intravenously; blood was then drawn at 30 and 60 minutes for estimation of TSH. These tests were done soon after admission at a median of 5 days.
All patients who recovered and were discharged home had the TRH test and gonadotrophins repeated in the outpatients department about 3 months after discharge (median 104 days) provided they had not suffered from any intercurrent acute disease. A total of 44 such patients (30 women, 14 men; mean age $82 \pm 5.7$ ) were thus followed-up. The remainder could not be retested because of intercurrent illness in 19, death before the second TRH could be carried out in eight or refusal to attend follow-up in three.

A group of age- and sex-matched ambulatory controls living at home were also recruited from local authority social centres and old people's homes. The same exclusion criteria as for the in-patients were used, plus the requirement that they had not suffered from any acute disease within the previous 3 months. The majority had some chronic illnesses and were taking medications so that they were not entirely disease free. They differed from the patients' group only in the sense that they had been free from symptomatic acute diseases for 3 months prior to the test. There were 71 controls ( 47 women, 24 men, mean age $82 \pm 5.0$ ). None of the controls were found to have biochemical evidence of previously unknown thyroid disease.

Thyroxine, LH, FSH and testosterone were estimated by conventional double antibody radioimmunoassay. TSH by a highly sensitive two-site enzyme amplification immunoassay (TSH Novoclone, Novobiolab, Cambridge). Normal adult ranges for our hospital laboratory were :

$$
\begin{aligned}
& \text { Total thyroxine } \quad 60-150 \mathrm{nmol} / \mathrm{l} \\
& \text { LH: Women, post menopause }>50 \mathrm{U} / 1 \\
& \text { Men 4-14 U/1 } \\
& \text { FSH: Women, post menopause }>20 \mathrm{U} / 1 \\
& \text { Men } 1.5-8 \mathrm{U} / 1 \\
& \text { TRH test } \\
& \text { Basal TSH } \\
& \text { Peak TSH increment }\left(\Delta_{\max } \quad>2 \mathrm{mU} / 1\right. \\
& \text { TSH) } \\
& \text { Testosterone (men) } \quad 10-28 \mathrm{nmol} / 1 \\
& 0.3-3.8 \mathrm{mU} / 1
\end{aligned}
$$

As the gonadotrophins assays were carried out in the routine hormone laboratory, exact values were not always available for women who had results within the normal range. Thus three patients and four controls were reported to have an $\mathrm{LH}>50 \mathrm{U} / \mathrm{l}$; in order that these data could be included in the analyses, this was set to 51 . Of the 34 female patients with an FSH within the normal range, 25 had inexact values: 18 were reported to have FSH $>20 \mathrm{U} / 1$ and $7>50$; these values were set to 21 and 51, respectively. Of the 43 female controls with a normal FSH, 32 had inexact values: 17 with FSH $>20 \mathrm{U} / 1,3>25$ and $12>50$; these were set to 21,26 and 51 , respectively. 


\section{Statistical methods}

Between-group and within-group comparisons were tested using the Wilcoxon rank sum test and the Wilcoxon signed rank test, respectively. Where differences could be reasonably expected to be normally distributed, parametric methods were used to calculate $95 \%$ confidence intervals for the mean difference. This study was approved by the hospital ethical committee, and written informed consent was obtained in every case.

\section{Results}

In the acute patients, the mean plasma total thyroxine levels were significantly lower than in the controls and in the patients followed up after recovery (Figure la and b). This represents the well-known transient depression of thyroid function due to acute illnesses, the so-called 'euthyroid sick syndrome'. ${ }^{10}$

\section{TRH test}

The $\Delta_{\max }$ TSH was significantly lower in the acute patients than in the controls and patients retested after recovery and discharge home (Figure $2 \mathrm{a}$ and b).

In the cohort which was followed up $(N=44)$, only two $(4.5 \%)$ acute patients had an elevated baseline TSH but four (9\%) after recovery; six $(14 \%)$ acute patients had a subnormal baseline TSH, but only three (7\%) at follow-up; nine (20\%) acute patients had a subnormal $\Delta_{\max }$ TSH, only four $(9 \%)$ after recovery. Among the controls $(N=71)$, six $(8 \%)$ had an elevated baseline TSH, 0 $(0 \%)$ a subnormal baseline TSH, and only seven $(10 \%)$ a subnormal $\Delta_{\max }$ TSH.

\section{Plasma gonadotrophins-women (Table I)}

Plasma LH was lower in the acute patients compared to controls $(P=0.17)$ and significantly higher in the patients followed up after discharge, when compared with their initial values $(P<$ $0.001)$. In our cohort of acute patients $(N=27)$, a subnormal LH was found in $26(96 \%)$, but in only $18(67 \%)$ after recovery.

Plasma FSH was also significantly higher in the controls $(P=0.05)$ and after recovery from acute diseases $(P=0.04)$. In our cohort of acute patients, a subnormal FSH was found in eight $(30 \%)$, but in only three $(12 \%)$ after recovery.

\section{Plasma gonadotrophins-men (Table I)}

Similar results were obtained in men, with plasma gonadotrophins being significantly higher in con-
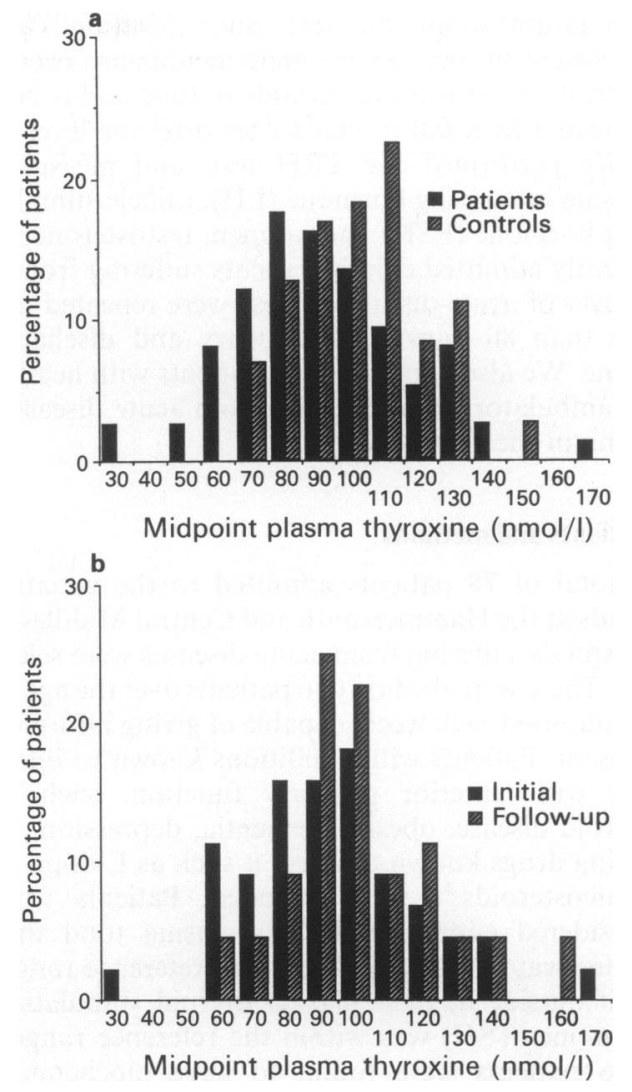

Figure 1 Plasma total thyroxine for (a) patients (mean $=91 \mathrm{mmol} / \mathrm{l}, N=74)$ and controls (mean $=103$ $\mathrm{nmol} / \mathrm{l}, N=71)$ (mean difference $=11.6 \mathrm{nmol} / 1,95 \% \mathrm{CI}$ $4.3,18.9 ; P=0.002)$, and (b) cohort of patients who were followed up (initial: mean $=94 \mathrm{nmol} / 1, N=44$; followup: mean $=102 \mathrm{nmol} / 1, N=44 ;$ mean difference $=8.2$ nmol $/ 1,95 \%$ CI $0.5,15.9 ; P=0.01$ ).

trols (LH: $P=0.01$; FSH: $P=0.05$ ) and at followup (LH: $P=0.03$; FSH: $P=0.01$ ). In our acute cohort $(N=13)$, only two $(15 \%)$ had subnormal LH values, but none at follow-up; similarly one $(8 \%)$ acute patient had a subnormal FSH, none after recovery.

\section{Plasma testosterone}

This was lower in the acute patients compared with controls $(P=0.02$, Figure 3$)$ and significantly improved after recovery (Table I, mean difference $=8.1, P=0.05,95 \%$ CI $0.37,15.7$ ).

\section{Discussion}

Our findings indicate that large numbers of elderly patients suffering from acute diseases are at risk of 
Table I Plasma gonadotrophins

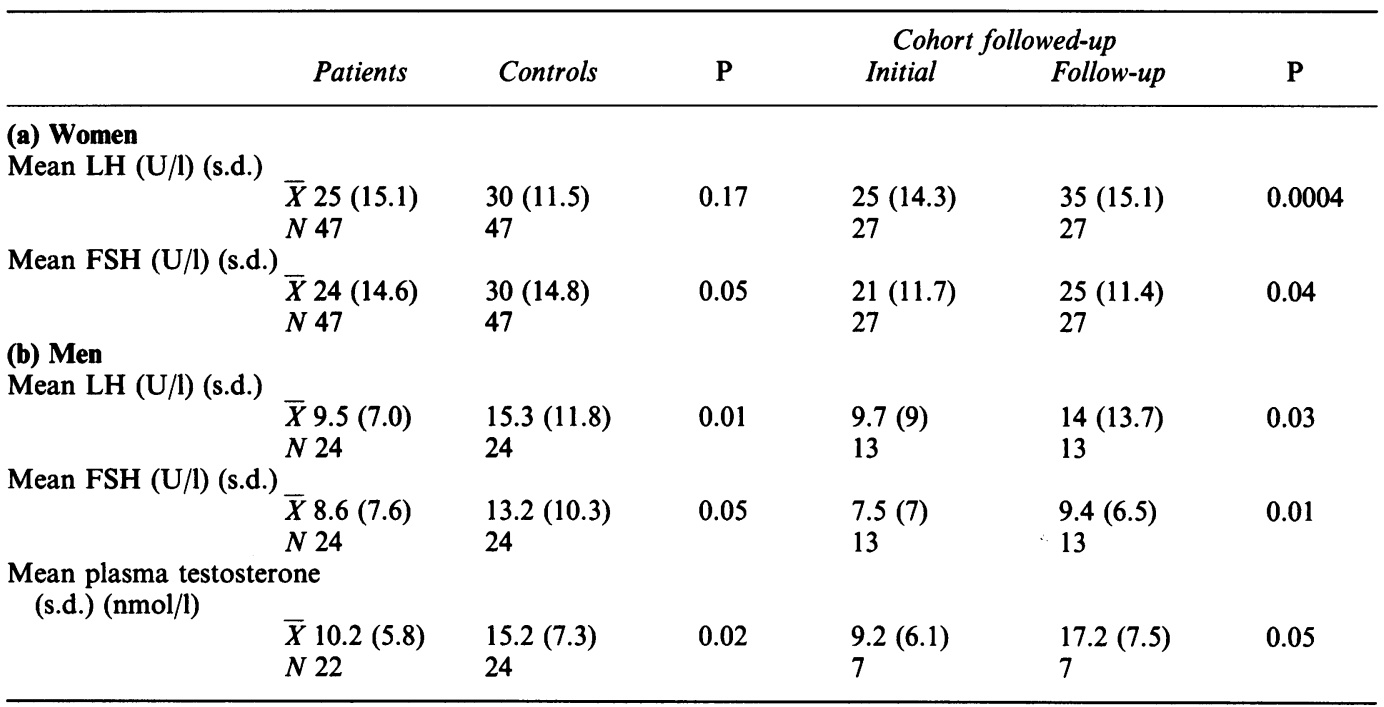

developing a state of transient anterior pituitary dysfunction. This is indicated by decreased values for baseline TSH, $\Delta_{\max }$ TSH and baseline gonadotrophins. Plasma thyroxine and plasma testosterone in men are also affected. These values tend to return towards normal on recovery.

It is probable that old age is accompanied by a progressive decline of the functional reserve of the anterior pituitary. This is supported by the fact that a sizeable proportion of our healthy controls had results which in young individuals would be interpreted as subnormal. It is impossible, however, to disentangle the effects of normal ageing from those of chronic diseases which may contribute to this decline of functional reserve: it is well known that about $70 \%$ of the over- $75 \mathrm{~s}$ suffer from chronic diseases. ${ }^{11}$ With decline of functional reserve any serious acute illness may more easily derange anterior pituitary function.

There is evidence that in younger subjects too a transient impairment of anterior pituitary function may occur during some critical acute diseases. ${ }^{12-14}$ Such studies, however, generally reported a decrease of single pituitary hormones. In the elderly this impairment is more global but seems to spare ACTH function. ${ }^{4}$ Its real incidence is likely to be greater than in the present series of patients, whose mortality was eight of $74(11 \%)$, about half that of all our acute patients which is about $20 \%$; our exclusion criteria had left out the most ill.

The absence of clinical signs of hypopituitarism in these patients resembles the lack of clinical signs of thyroid disease in the so-called 'euthyroid sick syndrome, ${ }^{10}$ in which a transient impairment of thyroid function tests occurs during the course of acute diseases. It would be inappropriate, however, to call this state 'eupituitary sick syndrome', as we have demonstrated altered anterior pituitary function in these patients.

The occurrence of this dysfunction can confuse the interpretation of endocrine function tests. ${ }^{15-17}$ For example, patients with a low plasma thyroxine and a normal TSH level may be suffering from the 'euthyroid sick syndrome' or be hypothyroid with an acute illness temporarily decreasing the TSH level. ${ }^{18}$ Plasma free thyroxine and tri-iodothyroxine should in theory help in clarifying the diagnosis but they too have often been found to be decreased in the presence of acute diseases: ${ }^{19,20}$ our experience is in keeping with this. Despite these problems, tests of anterior pituitary function and reserve remain of great value in the investigation and management of endocrine diseases in the sick elderly, but should be interpreted with caution. They may have to be repeated after recovery when abnormal and/or do not fit with the clinical picture.

Why does this pituitary impairment occur? The transient reduction of gonadotrophins levels, and testosterone in men, is a form of hypogonadotrophic hypogonadism, ${ }^{21}$ probably the remnant of the teleologically important decrease in sexual function which occurs during severe diseases in the young. ${ }^{22,23}$ Survival takes priority over reproduction in younger acutely ill subjects.

It is less clear whether there is a teleological purpose for the decreased pituitary production of TSH during acute diseases. There has long been a theory that the 'euthyroid sick syndrome' is 

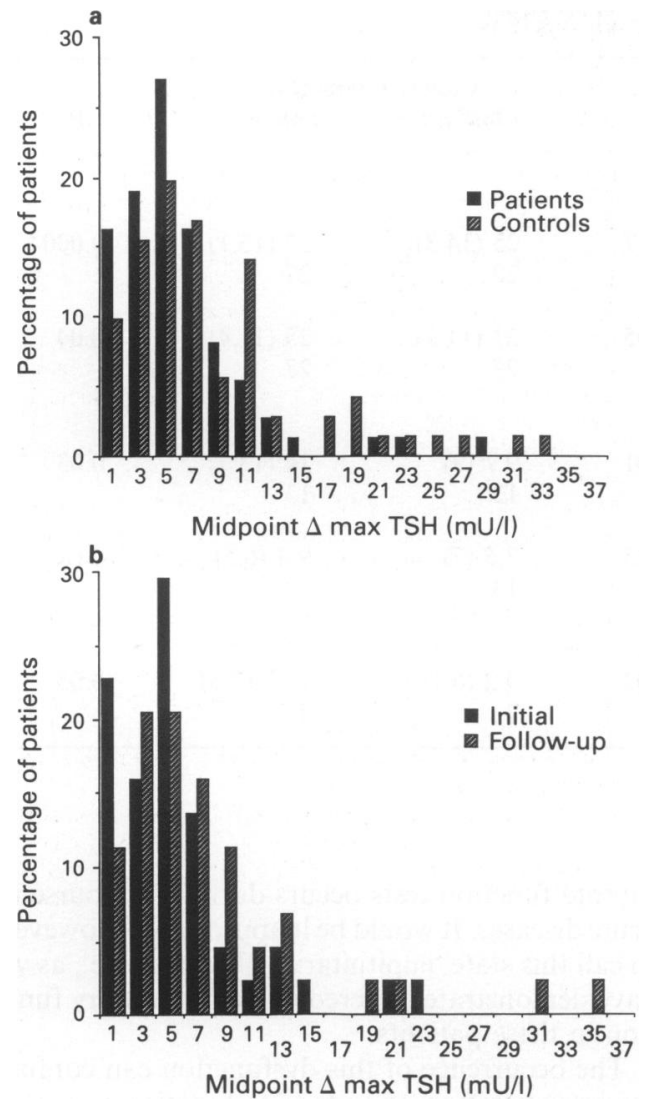

Figure $2 \Delta_{\max }$ TSH for (a) patients (mean $=6.0 \mathrm{mU} / 1$, $N=74$ ) and controls (mean $=8.7 \mathrm{mU} / 1, N=71$ ) (mean difference $=2.7 \mathrm{mU} / 1,95 \% \mathrm{CI} 0.7,4.7 ; P=0.01$ ), and (b) cohort of patients who were followed up (initial: mean $=5.7 \mathrm{mU} / 1, N=44$; follow-up: mean $=7.7 \mathrm{mU} / 1$, $N=44$; mean difference $=2 \mathrm{mU} / 1,95 \%$ CI $0.2,3.7$; $P=0.01)$.

beneficial for survival. ${ }^{24}$ This is difficult to reconcile with the fact that untreated myxoedema may suddenly worsen and at times proceed to coma during acute diseases, and greatly benefits from thyroid replacement therapy, which is life-saving in these circumstances. ${ }^{25} \mathrm{We}$ think that the dysfunction highlighted by this study could contribute to the high mortality of acutely ill elderly patients.

\section{References}

1. Sandler, L.M., Burrin, J.M., Joplin, G.F. \& Bloom, S.R. Combined use of vasopressin and synthetic hypothalamic releasing factors as a new test of anterior pituitary function. Br Med J 1986, 292: 511-514.

2. Harsoulis, P., Marshall, J.C., Kuku, S.F., Burke, C.W., London, D.R. \& Fraser, T.R. Combined test for assessment of anterior pituitary function. Br Med J 1973, 4: 326-329.

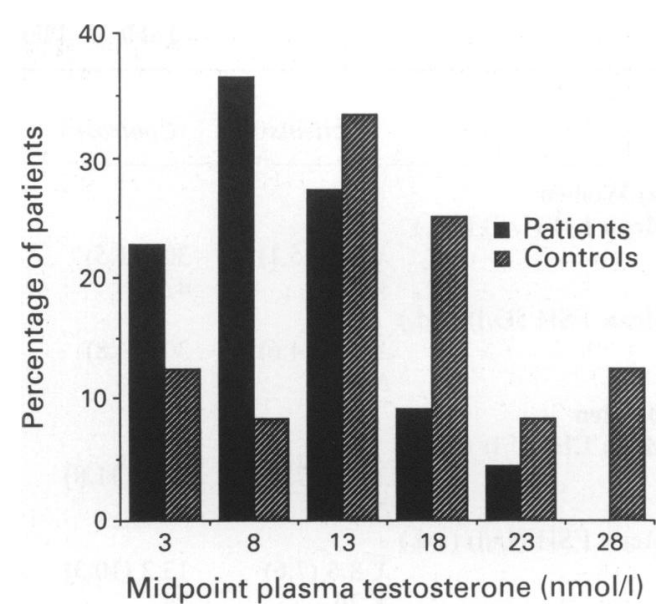

Figure 3 Plasma testosterone for male patients (mean = $10 \mathrm{nmol} / 1, N=22)$ and controls (mean $=15 \mathrm{nmol} / 1, N=$ 24) $($ mean difference $=5 \mathrm{nmol} / 1,95 \%$ CI $1.0,9.0 ; P=$ 0.02).

In conclusion our study has shown that acute diseases in elderly patients over the age of 75 often cause transient impairment of several anterior pituitary functions, as well as of the thyroid, and of the gonads in men. This may cause diagnostic? difficulties, and decreases the specificity of these tests. ${ }^{26}$ We think that the dysfunction highlighted by this study shows that the development of an effective therapeutic intervention is needed for some of these elderly patients. Our results showing the transient nature of this dysfunction may be used as an indication for the duration of treatment.

\section{Acknowledgements}

The authors would like to acknowledge the help received from the Division of Molecular Endocrinology at the Hammersmith Hospital, who performed the endocrine tests.

We would like to thank all the patients, the residents of the many old peoples' homes, of the Licensed Victuallers National Homes in New Denham, and the members of the Age Concern Ashford Day Centre, who contributed the healthy controls.

3. Jadresic, A. \& Impallomeni, M. Investigation of pituitary and adrenal function. In: Hodkinson, H.M. (ed.) Clinical Biochemistry of the Elderly. Churchill-Livingstone, Edinburgh, 1984, pp. 259-295.

4. Impallomeni, M., Yeo, T,. Rudd, A., Carr, P. \& Aber, V. Investigation of anterior pituitary function in elderly inpatients over the age of 75. $Q J$ Med 1987, 242: 505-515. 
5. Steger, R.W. \& Peluso, J.J. Sex hormones in the ageing female. Endocrinol Metab Clin North Am 1987, 16: $1027-1043$

6. Snyder, P.J., Reitano, J.F. \& Utiger, R.D. Serum LH and FSH responses to synthetic gonadotrophin-releasing hormone in normal men. J Clin Endocrinol Metab 1975, 41: 938-945.

7. Kenny, R.A. \& Fotherby, K. The sex steroids and trophic hormones. In: Hodkinson, H.M. (ed.) Clinical Biochemistry of the Elderly. Churchill-Livingstone, Edinburgh, 1984, pp. 246-258.

8. Hockaday, T.D.R. Assessment of pituitary function. $\mathrm{Br} \mathrm{Med}$ $J$ 1983, 287: 1738-1740.

9. Burrows, A.W., Shakespear, R.A., Hesch, R.D., Cooper, E., Aickin, C.M. \& Burke, C.W. Thyroid hormones in the elderly sick: 'T4 euthyroidism'. Br Med J 1975, 4: 437-439.

10. Wartofsky, L. \& Burman, K.D. Alterations in thyroid function in patients with systemic illness. The 'euthyroid sick syndrome'. Endocrinol Rev 1982, 3: 164-217.

11. Office of Population Censuses and Surveys. General Household Survey 1988, Series GHS No. 19. HMSO, London.

12. Finucane, P., Rudra, T., Hsu, R. et al. Thyrotrophin response to thyrotrophin-releasing hormone in elderly patients with and without acute illness. Age Ageing 1991, 20: 85-89.

13. Quint, A.R. \& Kaiser, F.E. Gonadotrophin determinations and thyrotrophin-releasing hormone and luteinising hormone-releasing hormone testing in critically ill post menopausal women with hypothyroxinaemia. J Clin Endocrinol Metab 1985, 60: 464-471.

14. Wehmann, R.E., Gregerman, R.I., Burns, W.H., Sarah, R. \& Santos, G.W. Suppression of thyrotrophin in the low thyroxine state of severe nonthyroidal illness. N Engl J Med 1985, 312: 546-552.

15. Cohen, J.L. Thyroid-stimulating hormone and its disorders. In: Becker, K.L. (ed.) Principles and Practice of Endocrinology and Metabolism. Lippincott Co, Philadelphia, 1990, pp. 144-152.
16. Dolecek, R. Endocrine changes in the elderly. Triangle 1985, 24: 17-33.

17. Mannakara, J.V. \& Datta-Chaudhuri, M. Recognising pituitary insufficiency in the elderly. JAGS 1991, 39: 273376.

18. Hooper, M.J. Diminished TSH secretion during acute nonthyroidal illness in untreated primary hypothyroidism. Lancet 1976, 1: 48-49.

19. Gregerman, R.I. \& Bierman, E.L. Aging and hormones. In: Williams, R.H. (ed.) Textbook of Endocrinology, 6th ed. W.B. Saunders, Philadelphia, 1981, pp. 1192-1212.

20. Kaptein, E.M. Abnormal thyroid function tests in euthyroid persons. In: Becker, K.L. (ed.) Principles and Practice of Endocrinology and Metabolism. Lippincott Co., Philadelphia, 1990, pp. 293-300.

21. Tsitouras, P.D. Effects of age on testicular function. Endocrinol Metab Clin North Am 1987, 16: 1045-1059.

22. Woolf, P.D., Hamill, R.W., McDonald, J.V., Lee, L.A \& Kelly, M. Transient hypogonadotrophic hypogonadism caused by critical illness. J Clin Endocrinol Metab 1985, 60: 440-450.

23. Morley, J.E. \& Melmed, S. Gonadal dysfunction in systemic disorders. Metabolism 1979, 20: 1051-1073.

24. Utiger, R.D. Decreased extra-thyroidal triiodothyronine production in nonthyroidal illness: benefit or harm? Ann Intern Med 1980, 69: 807-811.

25. Impallomeni, $M$. Unusual presentation of myxoedema coma in the elderly. Age Ageing 1977, 6: 71-76.

26. Fairweather, D.S. \& Campbell, A.J. Diagnostic accuracy. The effects of multiple aetiology and the degradation of information in old age. $J R$ Coll Physicians Lond 1991, 25: $105-110$. 